\title{
Research on Large Energy Power Enterprise Group total compensation conglomerates distribution systems Construction
}

\author{
Jia-xu CHENG ${ }^{1, a}$, Hao-jie Liu' ${ }^{2}$, Dan Wang ${ }^{1}$, Ying-hui HAN ${ }^{3}$ \\ 1 State Grid Energy Research Institute, Beijing, China \\ 2 State Grid Corporation of China, Beijing, China \\ ${ }^{3}$ Beijing Institute of Technology, Beijing, China
}

\begin{abstract}
In order to solve the problem of exist in W company salary distribution, such as the work guide is unknown, incentive enough, the target set properly and other issues, this paper especially focuses on the characteristics of enterprises, the company management and control model and other aspects to do in-depth study. On the basis of recognition control mode the pay distribution structure is determined, and then the appropriate indicators are sated. They are linked to further clarify the distribution of the guide, while the target value of properly designed and incentive mechanisms to ensure that the salary distribution model to follow on the basis of the relevant principles on the realization of economic promotion and to promote the strategic objectives.
\end{abstract}

\section{Introduction}

The Large Energy Power Enterprise Group total amount of remuneration in this article refers to enterprises or enterprise groups total paid remuneration to employees (including subsidiaries) directly in a given period, including enterprise (including subsidiaries) all wages, bonuses, overtime pay, job subsidies, labor insurance fees and expenses. On company-wide, it mainly refers to the sum of the total wages of all manner of employment programs. Reasonable salary distribution so that the total amount of remuneration into play to optimize the efficiency of labor costs, increase the role of incentive effect, and promote the healthy development of enterprises. W is large state-owned central enterprises, Large Energy Power Enterprise Group, its asset size reached 2 trillion Yuan, under a number of power enterprises, many industrial units, a number of financial institutions, more than the immediate professional support unit. The geographical scopes branched out into home and abroad, all kinds of branches and sub a total of more than 50 companies. And units' market positioning, stage of development, company size, positioning functions are varied. SASAC approved the annual W's total remuneration, and therefore need to complete a large total compensation distributed among the many molecules of the company ${ }^{[1]}$.

For W company, total compensation control often involves two core issues. Firstly, under the supervision of the SASAC, how to develop a reasonable total salary to increase incentive effect on the basis of strengthening labor costs management. Secondly, how to pay the total amount of control and optimization of the balance between the subsidiary companies. Total salary distribution business is a core component of the total compensation budget management.
Since the W company was in the implementation of the total payroll budget management system, it constantly has explored scientific and rational plan of total wages, and accumulated some experience. With the intensification of human resource management continued to deepen, there are challenges to the total wage budget management. Firstly, headquarters labor costs for each unit in order to control the total amount of remuneration as the main means of control, only the overall level, the growth rate of labor cost and other considerations of human capital investment amount, and failed business performance, labor efficiency, and stable operation level human capital output capacity combine there is a big limitation considerations; different characteristics of each business sector companies, the lack of differentiation of total compensation allocation criteria and the plate, based on optimal balance between the various units, the total amount of remuneration has not yet formed the group balance of the system optimization mechanism and management system ${ }^{[2]}$.

In this context, modern technology and human resource management concepts are used. Learning from the overall budget management theory, for critical issues, remuneration allocation model and optimization technology covering the total amount of enterprises are researched and developed including coordination grid enterprises, market-oriented industrial units, financial institutions. These will rich enterprise compensation management and human resource planning management theories, help companies improve the scientific, systematic and intensive lean level of human resource management ${ }^{[3]}$.

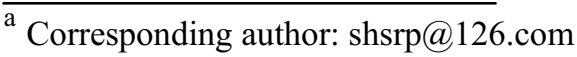




\section{Total salary distribution system}

\subsection{Total compensation distribution system build path}

Taking into account a complex industrial structure, salary distribution characteristics more realistic level, to build total remuneration allocation model should be in accordance with the "four steps" building strategies. It is hierarchical classification construction of the company's total salary distribution system. Specific process shown in Figure 1.

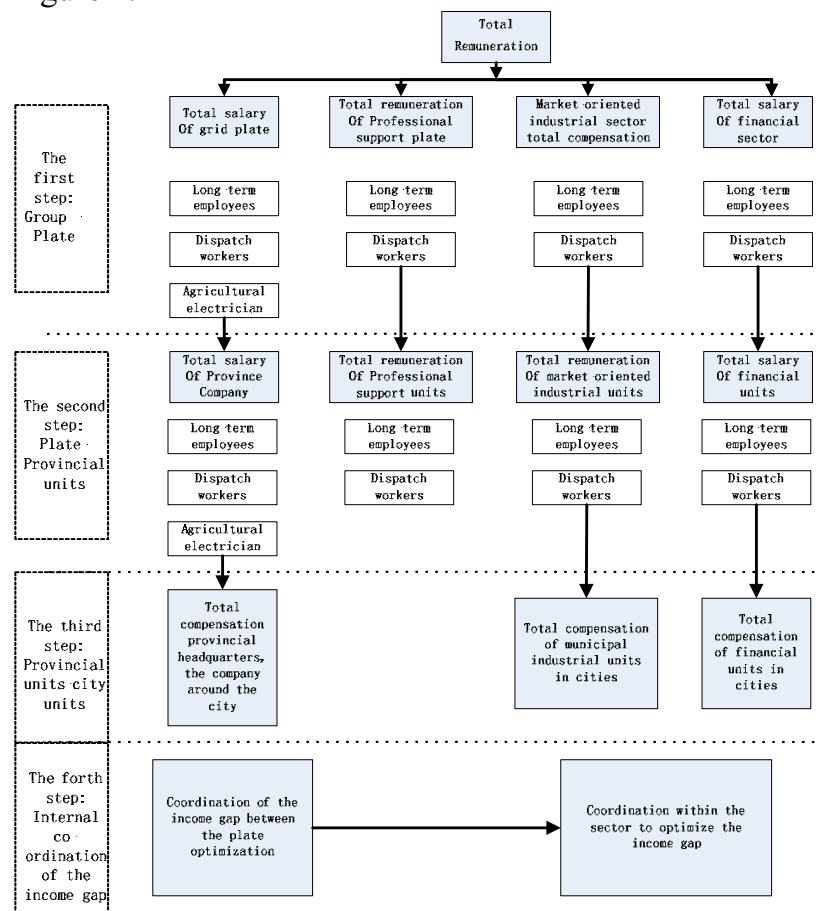

Figure 1. Overall configuration diagram of salary distribution model in company

\subsubsection{Consider the heterogeneity of the business segments, the completion of Group - business segments salary distribution}

The use of sections to divide the text of the paper is optional and left as a decision for the author. Where the author wishes to divide the paper into sections the formatting shown in Table 2 should be used.

The total remuneration of each segment constituted mainly by two content. One part as a standard part of the remuneration guarantee the income of workers, and the other part is the incentive for incentive compensation. Among them, the salary guarantee section includes the standard salary of long-term workers, the standard salary of dispatched workers, and agricultural electrician standard salary (grid plate only).

Total remuneration $=$ the total salary of grid plate + the total salary of professional support units + the total salary of market-oriented industrial sector + the total salary of the financial sector

The total salary of grid plate $=($ the standard salary of long-term workers + the standard salary of dispatched workers + agricultural electrician standard salary) + the incentive compensation of grid plate
The total salary of professional support units $=($ the standard salary of long-term workers + the standard salary of dispatched workers) + the incentive compensation of professional support units

The total salary of market-oriented industrial sector $=($ the standard salary of long-term workers + the standard salary of dispatched workers) + the incentive compensation of market-oriented industrial sector

The total salary of the financial sector $=($ the standard salary of long-term workers + the standard salary of dispatched workers) + the incentive compensation of financial sector

Specific building process includes the following:

(1) To construct a standard pay fitting model. Selecting historical level of wage income based on different forms of the plate and employment key factors, the standard salary fitting model of each employment respective area lines is obtained by multivariate regression.

(2) To calculate the standard salary for each form of employment on each segment. Through the independent variable predicts, fitted value of the standard salary $S_{0 i j}$ for each plate in the each form of employment is gotten. which, $i=1,2,3,4$, representing the grid plate, the professional support plate, market-oriented industrial sector and the financial sector units. $j=1,2,3$, representing long-term workers, labor dispatch and agricultural electrician.

(3) To calculation incentive compensation. The total standard compensation of the company is gotten by each employment form of the standard salary on each plate plus. The all standard total compensation can be subtracted from the total amount of remuneration assigned to give incentive pay. Salary differences assigned specific role in the adjustment of $\left(S-S_{0}\right)$, known as incentive compensation for each of the plates.

(4) To complete the company incentive compensation allocation. Differentiate between the plate-adjusted per capita incentive compensation coefficient setting can be adjusted later. Adjustment coefficient of the plate includes a comprehensive and objective performance evaluation coefficient and the plate subjective strategic development incentive coefficient.

(5)To complete the plate salary distribution. The various portions of the plate in the form of labor remuneration are multiplied by forecast number of staff. the standard salary for each of the plate employment lines and incentive compensation are gotten. After the two parts have been added to general remuneration allocation amount for each of the plate employment forms.

\subsubsection{Consider homogeneity within the sectors, the completion of the business segment - provincial unit salary distribution}

For the grid plate, taking regression analysis, the per capita standard remuneration in the provincial companies is fitted by regression analysis. The provincial company's standard salary is obtained by multiplying per capita standard remuneration with the number of persons. Then, 
based on performance and human resources output efficiency, the total amount of incentive compensation on the grid plate was cut. Finally, the provinces per capita salary are adjusted by the objective region differences and per capita income differential ${ }^{[4]}$.

For the professional support units, each unit based on the industries in which property and business service support features, is carded the immediate professional support plate. Immediate support plate professional salary management has many similarities with the grid plate. Therefore, in order to reflect the original management approach to succession and continuity, immediate professional support sector allocation model building process is similar to the grid plate. Immediate support professional sector allocation model in incentive compensation adjustment coefficient setting focuses more on support services for the company's strategic direction $^{[5]}$.

For market-oriented industrial units sector, considering its financial management control and strategic management control combining control mode, the Group Headquarters uses the "basic salary + incentive compensation" approach link the financial indicators and strategic indicators with basic pay and incentive pay. By enterprises self-reported economic target linked with base salary and incentive compensation, greatly stimulating endogenous power of the industry market segment unit enterprise. Its features of the market are more prominent. At the same time, the establishment of incentive factor in the market segment of industrial units decides mechanism, results from incentive compensation allocation linking the target completion. So, achieve economic efficiency has improved, on the other hand the realization of the company's strategic objectives has supported.

For the financial sector, considering its financial management control and strategic management control combining control mode, the Group Headquarters uses the "basic salary + incentive compensation" approach link the financial indicators and strategic indicators with basic pay and incentive pay. By enterprises self-reported economic target linked with base salary and incentive compensation, greatly stimulating endogenous power of the financial sector enterprise. Its features of the market are more prominent. At the same time, the establishment of incentive factor in the market segment of the financial sector decides mechanism, results from incentive compensation allocation linking the target completion. So, achieve economic efficiency has improved, on the other hand the realization of the company's strategic objectives has supported. Although the financial sector and the industry sector model idea is similar, in particular linked to indicators and incentive coefficient determining there are still significant differences in terms of mechanisms.

\subsubsection{Consider the relationship distribution between different levels, the completion of provincial - salary distribution units cities}

Power grid sector allocation model units around the city's mainly linked with job performance wage system. Basic security portion is related to salary point system.
Incentive awards and other matters are related to the per capita average increase performance incentive compensation, the falling levels of responsible persons annual performance evaluation score, and investment and output efficiency coefficient in human resources. Immediate support professional sector, market-oriented industrial sector and the financial sector units in the municipal units salary distribution model substantially build on a reference model distribution.

\subsubsection{Overall balance of the income gap among the plates, the completion of coordination and optimization of technology development}

At the same income level evaluation standard premise, the plate (enterprise) per capita income equivalent theory value is calculated. This theory value is income levels in this environment. When the magnitude of the ratio of the different sectors (business), that its income gap ratio. Based on Moderate Income Gap of coordination and optimization techniques in the study, five-dimensional indicator system is constructed. Using factor analysis, theoretical income level equivalent value calculation model has been built.

\subsection{The overall model structure of total compensation distribution system}

According to the group company's business scope and form of employment structure sector, for each business segment, salary distribution models of the way the labor performed were constructed. Among them, the total amount of remuneration in the Group covers four sectors category, such as grid plates, the business professional support sector, market-oriented industrial sector and financial institutions sector. Based on the actual employment situation of each sector, the total amount of remuneration Distribution Model covered for various ways of long-term employment of workers, labor dispatch electricians and other sections were constructed. Research mainly includes five models and a coordinated allocation optimization techniques, as follows in Table 2 below.

Table 1. Model composition table.

\begin{tabular}{|c|c|c|}
\hline No. & Achievement & \begin{tabular}{|c|}
$\begin{array}{c}\text { Achievement } \\
\text { category }\end{array}$ \\
\end{tabular} \\
\hline 1 & $\begin{array}{c}\text { The total compensation } \\
\text { distribution model in Group }\end{array}$ & \multirow{5}{*}{$\begin{array}{l}\text { Distribution } \\
\text { Model }\end{array}$} \\
\hline 2 & $\begin{array}{l}\text { The total compensation } \\
\text { distribution model in grid plate }\end{array}$ & \\
\hline 3 & $\begin{array}{l}\text { The total compensation } \\
\text { distribution model in business } \\
\text { professional support sector }\end{array}$ & \\
\hline 4 & $\begin{array}{l}\text { The total compensation } \\
\text { distribution model in market- } \\
\text { oriented industrial sector }\end{array}$ & \\
\hline 5 & $\begin{array}{c}\text { The total compensation } \\
\text { distribution model in financial } \\
\text { institutions sector }\end{array}$ & \\
\hline 6 & $\begin{array}{c}\text { Coordination and Optimization } \\
\text { Technology }\end{array}$ & $\begin{array}{c}\text { Optimization } \\
\text { techniques }\end{array}$ \\
\hline
\end{tabular}


On the relationship between the various models and the coordination and optimization technology, the distribution model from the company headquarters to the plate is the basis for salary distribution model. That determines the total amount allocated for the salary distribution model for each segment of each line of employment, but also for the salary distribution among sectors balance optimization. The each total labor remuneration allocation model for plates and lines of employment lays the foundation for the next step from the provincial units to municipal units in salary distribution model. Thus, the model building way from the plate, provincial to municipal level pay the total allocation layer by layer, on the one hand reflects the company's existing distribution model and method of succession and continuity, on the other hand deepens the model structure highlights the refinement and coordination of the remuneration distribution management optimization. At the same time, the coordination and optimization techniques solves fact lead to real limitations exist allocation model, and solves real problems for an orderly transition gap with the gap theory, achieves the income gap between the plate and the plate within the overall coordination.

\section{Advantage analysis for the total amount of salary distribution system}

3.1 The large and complex compensation distribution management process of Group is effectively decomposed, so that complex issues are broken down and the structure of the pattern are formed.

The original salary distribution in Group is only from headquarters to a provincial-level unit. The whole assignment process is single and general. And the way to build the total salary distribution model step by step increases the sector to provincial units, provincial to municipal units salary distribution model. This approach will be a complex process down to every level, step by step to show fully reflects the internal logic structure of salary distribution model, refine the salary distribution process and improve the transparency of salary distribution management.

\subsection{The new system has expanded the range of management salary distribution management company, detailed the management level, fully implemented human resources "three-wide" management requirements.}

Company existing salary distribution management system is to market-oriented as the classification criteria, all provincial units are divided into two categories as A, B. The amount of the total remuneration model above classification step to build is on the basis of the business characteristics, through the plate, provincial, municipal three levels, covering a variety of forms of employment. The new system has further expanded the longitudinal depth of salary distribution management, expanded the distribution management lateral coverage, detailed management level, deepen the human resource intensive management.

\subsection{The new system has strengthen the company's control over distribution targeted, enhanced the salary distribution differentiated control the level of fine}

To construct the overall model of Group total compensation by hierarchical classification reflects the Group assigned to different units differentiation control characteristics and control ideas in compensation distribution. This facilitates stratification of total Group salary distribution process are benefit to classification of control, prompt the company can be more direct and effective on all levels, in each category, salary allocation process various forms of employment improvement and optimization.

\section{Conclusion}

The contents of research are large, wide, deep level, efforts to solve the problem employee equity income of general interest. For this, first of all, top-level design is carried out, adding the plate level. The deconstruction of complex issues is carried out. At the same time, to carry out labor assign work hierarchically, in sub-lines, were constructed for each allocation model. In order to enhance the co-ordination of the distribution of work, especially the coordination and optimization techniques are developed. This innovative technology uses factor analysis method theoretical guidance value of large conglomerates income gap, as it is widely discussed and controversial issues of the income gap between the new idea. And the analysis is based on large amounts of data collected on the quantitative analysis of the revenue gap. However, due to the total amount of remuneration allocation model data collection is difficult, it brings greater confusion for the data analysis. So research group will continue to study further, to explore a more convenient, more efficient, more scientific allocation model.

\section{References}

1. Wang Jiaying. Research on total wage budget linkage mod el in WS Group subsidiary company[D]. Chang Chun : JiLin University, (2014).

2. Li Xin, Wu Fu-cheng, Yang Guang-ming. The Analysis on the Influence Factors of the Distribution of Gross Payroll in Power Supply Companies[J]. Hubei Electric Power, 9(2013).

3. Grossman H. A General Model of Insurrenction[J]. American Economic Review, 81(1991).

4. Agion, Pand Howitt P. Endogenous Growth Theory[M]. Cambridge: MIT Press, (1998).

5. Sala-ti-Martin.The Distributing Rised of Global Income Inequality[R]. NBER Working Paper WB. (2002). 